\section{ambient \\ SCIENCE \\ Vol. 05(Sp1):76-80 \\ Year 2018}

\title{
An Assessment of the Crisis Team towards the Disaster Preparedness: A Case Study of the Educational and Therapeutic Hospitals of Jahrom \\ city, Iran
}

\section{Fajriyeh Zahedinia', Esmail Rayat Dost', Samaneh Abiri'*, Masoud Ghanei', Mojtaba Zeini ${ }^{4}$, Ali Razeghi ${ }^{5}$, Navid Kalani ${ }^{6}$}

${ }^{1}$ Department of Nursing, Peimanieh Hospital, Jahrom University of Medical Sciences, Jahrom, Iran.

${ }^{2}$ Department of Emergency Medicine, Jahrom University of Medical Sciences, Jahrom, Iran.

${ }^{3}$ Anesthesiology, Critical Care and Pain Management Research Center, Jahrom University of Medical Sciences, Jahrom, Iran.

${ }^{4}$ Department of Nursing, Jahrom University of Medical Sciences, Jahrom, Iran.

${ }^{5}$ Student Research Committee, Jahrom University of Medical Sciences, Jahrom, Iran.

${ }^{6}$ Department of Health Services Management, Jahrom University of Medical Sciences, Jahrom, Iran.

Study Area:Jahrom, Iran

Coordinates: $28^{\circ} 30^{\prime} \mathrm{oo} " \mathrm{~N} ; 53^{\circ} 33^{\prime} 38^{\prime \prime} \mathrm{E}$

Keywords:

Approvals of the Ethical Committee at Jahrom University of Medical Sciences (IR.JUMS.REC.1396.107) and of the officials at the two hospitals were obtained before starting the research.

\section{Introduction:}

The word crisis is a multidimensional terminology also referred for various changes in the socio-physical environment and by its sad consequences for humanlife. It may come in any form or be of any scale. Some crises are due to some natural consequences while others are anthropogenic. Some crises can be predicted even a few days before they occur and some are unpredictable (Ritcher, 2008). The World Health Organization (WHO) considered crises and disasters as sudden ecological phenomena that require supranational assistance (Jahangiri \& Tabibi, 2003). The most dangerous nature of disasters is their unexpected and sudden occurrence (Dara $\&$ Ashton, 2005). Crises always gave negative impacts on general health and welfare to the affected populations (Hojat et al., 2008). Moreover, unexpected events are

\section{Abstract}

Iran is among the top ten disaster-prone countries in the world, due to its vast area, geographical position, and climatic diversity. Thus, studies regarding the disaster preparedness of the crisis team of the Educational and Therapeutic Hospitals becomes necessary. This descriptive, cross-sectional study was conducted by collecting the data by using the demographic questionnaire and a disaster based questionnaire which included 11 areas such aslogistic support, responding to the needs of injured people, organization, training, human resources, maneuver planning, maneuver implementation, medical evacuation, admission, transfer, discharge and communications. The highest level of preparedness (good level) was observed in the area of admission. Observed scores related to the areas of perceptions of managers and authorities, responding to the needs of injured people, training, logistic support, human resources, maneuver planning, maneuver implementation, transfer, discharge and communications, had evidenced a moderate levels of preparedness and areas of organization and medical evacuation revealed a poor levels of preparedness. The overall results concluded that the hospital is having a moderate level of disaster preparedness. However, due to the crucial role of hospitals at the time of crisis, hospital managers and authorities should make more efforts to train staff and to plan to increase preparedness levels.

generally classified under natural ones such as earthquakes, floods, and storms but nowadays the military-related biological attacks and leakage of radioactive materials (BMS, 2006), and have the two features of low probability of occurrence and heavy impact (Zaboli et al., 2006). Iran is one of the 10 disaster-prone countries of the world due to its wide expanse, geographical location and climatic diversity (Ardalan et al., 2009). Among the systems providing services in any country, the healthcare system plays a key and effective role in crisis management. As the most important component of healthcare systems, hospitals have remarkable effects on reducing the loss of life through introducing preparedness plans and strategies for coping with crises (Green et al., 2003; Hajavi et al., 2009). The plan for coping with crises includes the proper documentation 
to get sure that the responsible individuals and available facilities including the existing types of equipment would perform correctly during the crises. Replacement and reorganization of individuals would properly take place during and after the crises, and every individual would have specified duties during and after coping with urgent cases and natural disasters (Kavan et al., 2006). All the hospitals must have strategic, comprehensive, and standard plans for coping with unexpected events and should be able to respond rapidly when crises occur (Ameriyon et al., 2014). Furthermore, preparedness plans for hospitals must be tested periodically by their personnel under normal conditions and get qualitative and quantitative tests to identify their negative consequences so that their highest efficiency could be achieved (Jahangiri \& Tabibi, 2003). Hospitals are complicated and potentially vulnerable institutions. When an unexpected event happens, an interruption in standard communications and support services can disrupt operational plans of hospitals. In fact, the main goal of promoting crisis management for hospitals is to provide rapid and timely healthcare and treatment in order to reduce fatalities and complications caused by unexpected accidents (WHO, 2007). Assessment of hospital preparedness against disasters and likely events is one of the main elements that qualitatively upgrade this preparedness and encourage the management of hospitals to increase the capabilities for coping with them (Kollek \& Cwinn, 2011). A descriptive cross-sectional study on 12 military hospitals selected by cluster sampling in 2013 to assess their preparedness against unexpected events in America. Results indicated that the hospitals had an average preparedness level, and poor management and communications, structural problems, insufficient facilities, an unsuitable organization of human resources and of other resources were the most important problems they faced in coping with unexpected events (Ameriyon et al, 2014). In 2014, Daneshmandi et al. (2014) carried out a descriptive study to assess preparedness for coping with unexpected events in some selected hospital in Tehran. They used an observational assessment checklist with 210 questions as the data collection tool. Results showed that the hospital had an average preparedness level. Ingrassia et al. (2016) conducted a descriptive cross-sectional study on 15 hospitals in Italy using the checklist developed by the WHO to assess their preparedness in coping with crises. They reported that only three of the 15 hospitals had effective preparedness and the other 12 were not completely prepared. Abedi et al. (2015) carried out a descriptive analytical study to investigate the preparedness levels of the educational hospitals in Mazandaran Province to cope with crises resulting from unexpected events. The statistical population included 56 managers, heads of offices, and specialists in unexpected accidents. Results revealed that the hospitals lacked a desirable preparedness level to cope with crises.

As the most important center for human treatments are the hospitals so it must have the necessary and sufficient preparedness requirements before unexpected events happen. Assessment of preparedness levels of hospitals against disasters and likely events is one of the main elements which qualitatively upgrade the preparedness and encourage the management of hospitals to increase the capabilities for coping with them. Destruction or inactivation of hospitals in crises will create a feeling of social insecurity and instability because there are no facilities to replace hospitals. Therefore, this study was carried out to assess the preparedness level of the Peymanieh Hospital in Jahrom against unexpected events.

\section{Methodology:}

This descriptive cross-sectional study was conducted on 43 members of the crisis team at the educationaltreatment hospitals of Peymanieh and Motahari in Jahrom. The questionnaires on unexpected events were given to the crisis related teams of the mentioned hospitals and were willing to take part in the study. The checklist included demographic information and a questionnaire on unexpected events that covered the 11 areas of support and provisions (65 questions), meeting the needs of injured people (10 questions), organizing (34 questions), education (41 questions), human resources (29 questions), maneuver design (10 questions), maneuver execution (8 questions), evacuation of injured people (6 questions), admission (17 questions), transfer and discharge (25 questions), and communications (27 questions). The answer to each question in the checklist was given a score among one to three (no, somewhat, yes). The total of given scores was considered as weak (o-50\% of the total possible score), average $(50-75 \%$ of the total possible score), and good ( $75-100 \%$ of the total possible score). The score system is based on Ameriyon et al., 2014 who were confirmed the reliability and validity of the questionnaire. The SPSS 21 and descriptive statistics tests were employed to analyze the information.

\section{Results:}

Total forty-three members belong to the crisis teams at two educational-treatment hospitals in Jahrom participated in the study. Their average age was $38.34 \pm 5.47$ years, $51.2 \%$ were females and $48.8 \%$ males, and they had $14.24 \pm 5.01$ years of clinical experience at the hospitals on an average. Out of these 43 participants, $83.7 \%$ had Bachelor of Science degrees, $11.6 \%$ Master's degrees, and $4.7 \%$ of participants were only with high school diplomas. Further, $53.5 \%$ had taken part in special education courses on hospital crisis management, $79.1 \%$ were officially employed, $4.7 \%$ had training contracts, and $16.3 \%$ contracts and $51.2 \%$ had experience in coping with crises. 
The members of the crisis teams of these two hospitals gave an average score $(65.1 \%)$ to the general preparedness level of these two hospitals. The highest preparedness levels of the hospital were in the area of admission (given the good score of $83.7 \%$ ). The participants gave the various areas of the preparedness levels to the hospitals with the following average scores: $51.2 \%$ for the managers and the personnel in charge of crises, $55.8 \%$ for meeting the needs of injured people, $46.5 \%$ for organizing, $60.5 \%$ for education, $60.5 \%$ for support and provisions, $67.4 \%$ for human resources, $55.8 \%$ for maneuver design, $65.1 \%$ for maneuver execution, $46.8 \%$ for evacuation of injured people, $72.1 \%$ for transfer and discharge, and $55.8 \%$ for communications (internal and external). The areas of maneuver design and evacuation of injured people in the preparedness levels of the hospitals were given the poorest scores of $20.9 \%$ and $25.6 \%$ by the members of the crisis teams, respectively.

Table-1: Areas of preparedness levels in the hospitals against Unexpected events

\begin{tabular}{|c|c|c|c|}
\hline \multirow[t]{3}{*}{ Areas of preparedness } & \multirow{3}{*}{$\frac{\text { Poor }}{(0-50 \%)}$} & \multicolumn{2}{|l|}{ Score } \\
\hline & & Average & Good \\
\hline & & $(50-75 \%)$ & $(75-100 \%)$ \\
\hline $\begin{array}{l}\text { Managers and the personnel in } \\
\text { charge of crises }\end{array}$ & $7.0 \%$ & $51.2 \%$ & $41.9 \%$ \\
\hline $\begin{array}{l}\text { Meeting the demands of } \\
\text { injured people }\end{array}$ & $7.0 \%$ & $55.8 \%$ & $37.2 \%$ \\
\hline Organizing & $2.3 \%$ & $46.5 \%$ & $51.2 \%$ \\
\hline Education & $7.0 \%$ & $60.5 \%$ & $32.6 \%$ \\
\hline Support and provisions & $4.7 \%$ & $60.5 \%$ & $34.9 \%$ \\
\hline Human resources & $0.0 \%$ & $67.4 \%$ & $32.6 \%$ \\
\hline Maneuver design & $20.9 \%$ & $55.8 \%$ & $23.3 \%$ \\
\hline Maneuver execution & $14.0 \%$ & $65.1 \%$ & $20.9 \%$ \\
\hline Evacuation of injured people & $25.6 \%$ & $46.5 \%$ & $27.9 \%$ \\
\hline Admission $\quad 2.3 \%$ & $14.0 \%$ & $83.7 \%$ & \\
\hline Transfer and discharge & $2.3 \%$ & $72.1 \%$ & $25.6 \%$ \\
\hline Communications (int. \&ext.) & $9.3 \%$ & $55.8 \%$ & $34.9 \%$ \\
\hline
\end{tabular}

\section{Discussion:}

The frequency of natural disasters is rapidly rising. Asia accounts for $40.7 \%$ of the global disasters and $90 \%$ of disaster victims have always been porn to them (GuhaSapir et al., 2014). This research studied preparedness levels of crisis teams in two educational-treatment hospitals in Jahrom against unexpected events. Results indicated that the preparedness level in the area of admission was good $(83.7 \%)$. It was the highest score received among the various areas. This result strengthened the study Ameriun et al. (2010). However, our results contradict the results Hajavi et al. (2009). Chapman \& Arbon, (2008) suspected the possible reason why many of the patients have to be discharged immediately following each incident or crisis in order to admit other injured people. In our study, the score for the preparedness level of the hospitals in the area of meeting the needs of injured people was $55.8 \%$. This is an average level of preparedness, and it appears that more accurate planning is required to raise it to an acceptable one. As for the area of managers and the personnel in charge of dealing with crises, the reported preparedness level was $51.2 \%$, which is an average level. Salari et al. (2009) reported in their study that the preparedness level in the area of management was $61.9 \%$ and it is in agreement with our present research. Prerequisite compiled plans for treatment centers to cope with unexpected events, and their preparedness must be an important agenda for the hospital managers (Spinks, 2015). Furthermore, it is noteworthy that triage is the key to success in attending a large number of injured people with limited resources (Djalali et al., 2011). Based on the checklist, the mean score received in the area of organizing our study was $46.5 \%$. In the study conducted by Mehrabi et al. (2015) in a military hospitals, earned score of $89.7 \%$. Amiri et al. (2013) also reported a desirable score for the organizing area. Perhaps, the organizing capacity of military hospitals is more accurately and coherent as compared to the educational-treatment ones. The mean score given to the education area was $60.5 \%$. Ameriun et al. (2010) also reported this indicator received a desirable score and Aldridge (2007) pointed out in his research that the knowledge level of hospital personnel should be regularly assessed and the necessary education on hospital policies, procedures, and protocols be provided. Ghanbari et al. (2011) reported in their study that the preparedness level of the nurses to be present in crisis situations was $75 \%$. This was higher than the preparedness level noticed in the present research. Therefore, it is felt that desirable recognition and implementation abilities are needed during emergencies and crises. The efficiency of the personnel in a hospital would increase considerably if they all know that security, reliability, and performance ability of the technical systems in the hospital are at desirable levels. The score of $60.5 \%$ (an average one) was given to the support and provisions area of preparedness levels in the two hospitals. Various types of score were reported in the regards (Hojat et al., 2008; Hekmatkhah et al., 2012). Therefore, it seems that for improved general health and life expectancy of the patients require allocating budgets and procuring facilities needed for equipping hospitals (Vahedparast et al., 2013) which can reduce the number of fatalities in disasters.

The preparedness level of the two hospitals in the area of human resources received the score of $67.4 \%$. Earlier various types of score were reported in the regards (Daneshmandi et al., 2015; Soleimani, 2006). However, the expenditures and investments would be useless if personnel empowerment gets ignored because equipment will not prove helpful in the absence of efficient and motivated personnel (Akhavan \& Dehghani, 2015). The preparedness levels of the two hospitals in the area of maneuver design in the present research received an 
average score. Mastaneh \& Mouseli, (2013) justified this issue nicely in their study.

No educational maneuvers related to unexpected events were reported by Gomez (2011) in 34 trauma centers during the two years prior to the study. Therefore, educational maneuvers are essential to upgrade preparedness levels as much as possible and it should not be limited to educational workshops. As for the transfer and discharge area of preparedness, the two hospitals received an average score which support the earlier report of Salari et al., (2010), whereas the reports of Hosseini Shokouh et al. (2008) and Hojat et al. (2008) reported poor scores in this regard. Therefore, it seems that proper planning in the area of patient transfer and discharge can substantially decrease the number of deaths in crises. Interestingly, the mean score for evacuation was poor whereas discharge received an average score. In the area of communications, the preparedness levels of the two hospitals received the score of $55.8 \%$ which is nearer to the study of Hojjat et al. (2008) but too less than the report of Ameriun et al. (2010) carried out in the border hospitals. Communications play a basic role in unexpected events and hospitals must have alternative communications systems to use in an emergency. There must be internal communications between the various hospital departments. These systems, considered among other alternative communication tools, include loudspeakers, internal telephone lines, and also wireless two-way wireless radios. Moreover, communication devices must be provided to recall personnel who are not on the duty. In this relation, a pre-determined plan could be executed so that each person can inform two or three of his/her close colleagues of the existing conditions (Zaboli et al., 2006).

\section{Conclusion:}

Members of the crisis teams at two educational-treatment universities in Jahrom reported that these universities had average preparedness levels. It seems that more desirable results in crisis management could be achieved if planning would be carried out with greater care. These improved results will help hospitals to act more coherently when unexpected events occur.

\section{Acknowledgment:}

We would like to express our gratitude to the Clinical Research Development Unit at the Peymanieh Educational, Research, and Treatment Center of Jahrom University of Medical sciences for providing the facilities required to carry out this research.

\section{References:}

Abedi, G., Moosazadeh, M., Ranjbar, M. \& Abedini, E. (2017): Developmental Levels of Educational Hospitals for Confronting the Unexpected Disasters in Mazandaran Province. J. Mazandaran Univ. Med. Sci., 27(148): 79-87.

Akhavan, P. \& Dehghani, M. (2015): Evaluation Knowledge Management Processes and Identifying the Effective Factor for their Improvement: Iranian Police Case Study. Int. J.
Manag. Acad.,2 (1):10-27.

Aldridge, J. (2007): Hospital Security: The past, the present, and the future, part 2 of 2. Washington, DC: Security A s s e s s m e n t I n t e r n a t i o n a $\mathbf{l}$. http://www.saione.com/articles/HSPPF_Part2.pdf

Ameriun, A., Delavari, A. \& Teymourzadeh, E (2010): Rate of preparedness for crisis in three selected border hospitals. Iran. J. Military Med., 12(1):19-22.

Ameriyon, A., Aghighi, A., Tofighi, S., Sadeghi, A.A., Shahedi, A., Rasekh, F., Tavasoli, M \& Amanat, N. (2013): Assess the disaster preparedness of the selected military hospitals. LArmy Univ Med Sci. , 11(4):353-356

Amiri, M., Raei, M., Shirvani, N., Seiyed, D., Mohammadi, G.R. \& Afkar, A. (2013): Preparedness of Hospitals in North of Iran to Deal With Disasters. Iran. Red. Crescent Med. J.,15(6): 519521.

Ardalan, A., Masoomi, G., Goya, M., Ghaffari, M., Miadfar, J., Sarvar, M., Soroush, M., Maghsoodi, A., Holakouie Naieni, K., Kabir, M.J., Khankeh, H.R., Abolshams, B. \& Aghazadeh, M. (2009): Disaster Health Management: Iran's Progress and Challenges. Iran. J. Pub. Health, 38(Suppl.1):93-97. [Persian].

BMS (2006): Basij Medical Society: Set of guidelines for crisis management in medical centers. Pub. by: Helal Institute of Applied Science \& Technology, Tehran, Iran [Book in Persian].

Chapman, K. \& Arbon, P. (2008): Are nurses ready? Disaster preparedness in the acute setting. Australasian Emer. Care, 11(3):135-144.

Dara, S. \& Ashton, R. (2005): Worldwide disaster medical response: an historical perspective. Crit. Care Med., 33(1 Suppl):S2-6.

Daneshmandi, M., Nezamzade, M. \& Zareeian, A. (2014): A survey of selected hospitals in disaster preparedness. JMil Care,1:2835 (Persian).

Djalali, A., Khankeh, H., Öhlén, G., Castrén, M. \& Kurland, L. (2011): Facilitators and obstacles in pre-hospital medical response to earthquakes: a qualitative study. Scand.J. Trauma Resuscit. Emer. Med., 19 (1):30.

Ghanbari, V., Maddah, S.S., Khankeh, H.R., Karimloo, M. \& Ardalan, A. (2011): The Effect of a Disaster Nursing Education Program on Nurses' Preparedness for Responding to Probable Natural Disasters. Iran J. Nurs., 24(73):72-80. (Persian).

Gomez, D., Haas, B., Ahmed, N., Tien, H. \& Nathens, A. (2011): Disaster preparedness of Canadian trauma centers: the perspective of medical directors of trauma. Can I Surg. 54(1):9-16.

Green, G.B., Modi, S., Lunney, K. \& Thomas, T.L. (2003): Generic evaluation methods for disaster drills in developing countries. Ann. Emerg. Med., 41 (5): 689-699.

Guha-Sapir, D., Hoyois, P. \& Below, R. (2014): Annual Disaster Statistical Review 2013- The numbers and trends. Brussels, (CRED).

Hajavi, A., Shojaei-baghini, M.,Haghani, H. \& Azizi, A.A. (2009): Disaster management in the medical records department of Kerman s and Boroojerd educational hospitals and a Model Presentation. Quart. J. Health Manag.,12(35):9-16. (Persian).

Hekmatkhah, A., Rahimi, H., Kamali Aghdam, M., Taghavi 
Shahri, S.M., Sadeghifar, J. \& Hamouzade, P. (2012): Assessing the preparedness rate against earthquake risk in hospitals affiliated to Urmia University of Medical Sciences 2011. J. Urmia Nurs. Midwifery Fac.,10(2):0-o (Persian).

Hojat, M., Khaghanizadeh, M., Karimi Zarchi, M. \& Sirati, M. (2008): Readiness of subsidiary hospitals of Medical Sciences Universities. Daneshvar Med., 15(74):1-10.(Persian).

Hosseini Shokouh, S.M., Arab, M., Rahimi, A., Rashidian, A. \& Sadr Momtaz, N. (2008): Preparedness of the Iran University of Medical Sciences Hospitals Against Earthquake. Sci. J. School Pub. Health Inst. Pub. Health Res.,6(3-4):61-77.

Ingrassia, P.L., Mangini, M., Azzaretto, M., Ciaramitaro, I., Costa, L., Burkle, F.M., Corte, F.D. \& Djalali, A. (2016): Hospital disaster preparedness in Italy: A preliminary study utilizing the World Health Organization Hospital Emergency response evaluation toolkit. Minerva Anestesiol., 82(12):12591266.

Jahangiri, K. \& Tabibi, S.J. (2003): Crisis management: a model for planning effective in countering. Bioterrorism. 2(3):205-14. (Persian).

Kavan, M.G., Guck, T.P. \& Barone, E.J. (2006): A Practical Guide to crisis Management. Am. Fam. Physician., 74(7):1159-1164.

Kollek, D. \& Cwinn, A.A. (2011): Hospital Emergency Readiness Overview study. Prehosp. Disaster Med., 26(3):159-165.

Mastaneh, Z. \& Mouseli, L. (2013): Capabilities and limitations of crisis management in the Teaching Hospitals of Hormozgan University of Medical Sciences, 2010. Sci. Res. Essays, 8(26):1196-1202.
Mehrabi, F., Ghasemi, M. \& Rezaee, M. (2015): The Assessment of Readiness Indicators in Military Hospitals against Natural Disasters in Iran. J. Mil Med., 17(1):35-40

Richter, P. (2008): Hospital Disaster Preparedness: Meeting a Requirement or Preparing for the Worst? An Update (Eleven Years after). Pub. by: American Society for Healthcare Engineering, Chicago.

Salari, H., Heydari, A.R., Jolaei, H., Rahimi, S.H. \& Shafaghat, T. (2010): Readiness of governmental and private hospitals of Shiraz to deal with disasters in 2009. Sci. J. Rescue Rel., 2(4):110.

Soleimani, V.R. (2006): Assessment of preparation rate of Chamran hospital in Saveh in disaster in 1385. Second International Congress of crisis manegement in natural disastar. Tarvij, Iran (Persian)

Spinks, M. (2015): Crisis management. Emerg. Nurse. 22(9):12.

Vahedparast H, Ravanipour M, Hajinezhad F, Kamali F, Gharibi T, Bagherzadeh R. (2013): Assessing hospital disaster preparedness of Bushehr province. Iran. South Med. J., 16(1):69-76 (Persian).

WHO, (2007): Mass casualty management systems. Strategies and guidelines for building health sector capacity. Pub. by: World Health Organization, Geneva.

Zaboli, R., Tofighi, Sh., Ameriyon, H. \& Moghadasi, H. (2006): Assessment of preparation rate for Disaster management in Tehran city. Military Med. J., 8(2):103-11. (Persian). 